\title{
GENESIS OF PAIN IN ARTHROSIS
}

Gilberto Luis Camanho', Marta Imamura' ${ }^{2}$ Lars Arendt-Nielsen ${ }^{3}$

\section{ABSTRACT}

Advances in knowledge regarding the pathophysiology of pain among patients with knee osteoarthritis suggest that the central nervous system is involved as a source that maintains and amplifies the painful condition such that it is refractory to conventional orthopedic and rheumatological treatment. Initially, hyperalgesia is observed only at the affected site. However, when the pain becomes refractory, peripheral and central sensitization mechanisms contribute towards maintaining and amplifying the painful conditions, regardless of the peripheral process that originated the pain. At this stage, even removal of the etiological agent may no longer be enough to relieve the painful symptoms. It then becomes necessary to envisage that other factors, distant from the affected joint, may be responsible for the disabling painful condition in such patients. At present, osteoarthrosis does not have any known cure, and the aim of treatment is to lessen the pain while improving function and health-related quality of life, and whenever possible, to minimize the toxicity of the therapy. In the light of emerging evidence suggesting that the central nervous system has a role in the physiopathology of pain in patients with knee arthrosis, the central nervous system should be taken into consideration as a therapeutic target, instead of only administering local treatment using ordinary analgesics, anti-inflammatory drugs and non-pharmacological measures. Thus, methods that modulate the spinal cord and cerebral cortex, including the use of antidepressants, may have a role in managing these patients.

Keywords - Arthrosis; Knee/physiopathology; Pain/therapy

\section{INTRODUCTION}

Osteoarthrosis is the most prevalent joint disease and is the main cause of functional incapacity ${ }^{(1,2)}$ among elderly people ${ }^{(3)}$. Knee osteoarthrosis is the fourth commonest cause of health problems among elderly women ${ }^{(4)}$. The risk of incapacity consequent to osteoarthrosis alone is greater than from any other medical condition ${ }^{(3)}$. Currently, there is no known cure for osteoarthrosis, and the aim of treatment is to improve pain, function and health-related quality of life, while minimizing the toxicity of the therapy whenever possible ${ }^{(3)}$.

Osteoarthrosis is defined as failure of the joint cartilage resulting from mechanical, genetic, hormonal, bone and metabolic factors, which gives rise to an imbalance between the degradation and synthesis of joint cartilage and subchondral bone. It is manifested by morphological, biochemical, molecular and biomechanical abnormalities of cells and the extracellular matrix, which lead to softening, fibrillation, ulceration and loss of the joint cartilage, and to sclerosis of the subchondral bone and formation of osteophytes and subchondral cysts.

\section{PHYSIOPATHOLOGY}

Despite deep knowledge of the physiopathology of arthrosis at molecular level, there is still little knowledge about the genesis of pain in such patients.

1 - Titular Professor of the Department of Orthopedics and Traumatology, School of Medicine, University of São Paulo.

2 - Collaborating Professor in the School of Medicine, University of São Paulo.

3 - Head of the Sensory-Motor Interaction Center, Department of Health Sciences and Technology, University of Aalborg, Denmark.

Correspondence: Rua dos Cariris 177, Pinheiros, 05422-020 São Paulo, SP. E-mail: martaimf2@gmail.com

Work received for publication: August 23, 2010; accepted for publication: September 20, 2010. 
Classically, it is known that the possible causes of pain in arthrosis are related to increased intraosseous pressure due to vascular congestion of the subchondral bone, growth of osteophytes, synovitis and inflammation, capsular fibrosis, contracture and muscle weakness.

In a previous study, we showed that hyperalgesia of central origin was responsible for $61 \%$ of the pain reported by such patients on self-assessment scales like the visual analogue pain scale, WOMAC (Western Ontario McMaster Osteoarthritis Index) and SF-36 (Medical Outcomes Study 36-item Short Form Health Survey $)^{(5)}$. This suggests that both the central nervous system and the peripheral system are probably involved in maintaining the state of chronic pain in these patients. It seems that initially, hypersensitivity is only observed at the site affected. However, when the pain becomes refractory, mechanisms for central and peripheral sensitization start to contribute towards maintaining painful conditions, independent of the peripheral process that originated the pain.

Differently from acute pain, for which the physiopathology is relatively well known and the therapeutic results are more encouraging, chronic pain does not translate the magnitude of the tissue lesion and treatments remain unsatisfactory. Recently, development of new diagnostic methods for clinical investigation of central sensitization has furnished new knowledge for better understanding of the physiopathology of chronic pain. This new information has demonstrated that functional abnormalities in the central and peripheral nervous systems may play an important role in maintaining chronic pain.

Better comprehension of the complex mechanis$\mathrm{ms}$ involved in generating, modulating, amplifying and perpetuating pain has an important role in determining the best therapeutic regimen to use in treating patients with knee arthrosis. Modern treatment for pain, for example, is no longer based solely on symptom relief but on controlling it based on the physiopathological mechanisms involved ${ }^{(6)}$.

Recently, it was observed that intense and persistent nociceptive stimuli coming from peripheral tissues could trigger neuroplastic abnormalities in the central nervous system ${ }^{(7,8)}$. These abnormalities include increased excitability of the neurons in the posterior horn of the spinal cord, thus producing hyperalgesia, temporal summation of the pain and ascending regulation.

These neurochemical changes suggest that the pain induces and is partially maintained by a state of central sensitization $^{(9)}$, in which increased transmission of nociceptive information allows neurons that are not normally involved in transmitting pain information to start to do so. In this way, stimuli such as pressure on certain parts of the body, which in healthy volunteers are not interpreted as painful, start to be perceived as such ${ }^{(5)}$. It is worth emphasizing that peripheral nociceptive stimuli may begin and maintain the state of central sensitization, as has already been described in relation to fibromyalgia ${ }^{(7,10-12)}$.

Although chronic painful symptoms are subjective by nature, they may correlate with neuroimaging evidence that reveals increased levels of cerebral activation responses $^{(13-15)}$.

Several authors have already demonstrated that central sensitization may be involved in the genesis, maintenance, amplification and exacerbation of painful symptoms in patients with arthrosis in various body segments ${ }^{(15-19)}$. Like in our study (Imamura et $\mathrm{al}^{(5)}$ ), cutaneous and deep hyperalgesia has been observed in the forearms of patients with rhizarthrosis $^{(17)}$ and in the anterior tibial muscle of patients with knee $\operatorname{arthrosis}^{(19)}$.

It is interesting to note that painful sites with lower tolerance of pressure present high levels of substance P, calcitonin, bradykinin, tumor necrosis factor, interleukin-1, serotonin and norepinephrine, in comparison with healthy individuals without spontaneous pain or asymptomatic subjects ${ }^{(20)}$. In individuals with spontaneous pain, areas distant from the painful site also demonstrate significant increases in the levels of these chemical mediators ${ }^{(21)}$.

It is known that these abnormalities occur not only in the spinal cord $^{(22)}$, but also in other structures of the central nervous system. For example, a pilot study has already revealed that areas of the brain were involved in pain processing in a group of 12 patients with knee osteoarthrosis ${ }^{(23)}$. The results showed that the arthritis pain was associated with increased activity in the cingulate cortex, thalamus and amygdale, which are areas involved in processing the emotional aspects of pain ${ }^{(23)}$.

The presence of peripheral and central sensitization 
in patients with chronic pain induces additional neuroplastic changes in the posterior horn of the spinal cord and in cortical areas that then maintain and amplify the painful state, thus forming a vicious circle with refractory symptoms. At this stage, even removal of the etiological agent may no longer be enough to relieve the painful symptoms. It therefore becomes necessary to consider that other factors, distant from the joint that is affected, may be the agents responsible for the painful and incapacitating symptoms in these patients ${ }^{(5,24)}$, not only at the originating point ${ }^{(24)}$, but also for central sensitization ${ }^{(5)}$.

\section{WARNING SIGNS FOR THE DIAGNOSIS OF PAIN IN KNEE ARTHROSIS: PHYSICAL EXAMINATION TIPS FOR ORTHOPEDISTS}

Within this context, diagnosing peripheral and central sensitization is very important ${ }^{(25,26)}$, because when this is present, it means that neurons of the posterior horn of the spinal cord that would normally only be activated by nociceptive stimuli can now be activated by other stimuli, including non-nociceptive stimuli. This phenomenon is widely known as allodynia $^{(27)}$. This explains why, in cases in which central sensitization has become established, minimal peripheral stimuli are sufficient to maintain the painful and incapacitating condition ${ }^{(8)}$.

Warning signs are clinical indicators of problems that are more serious and which require greater medical attention. These signs were developed for use in cases of acute lumbalgia. However the same concepts can be applied in a more wide-ranging manner in searching for pain centers or localized hyperalgesia that has disseminated to parts of the body other than the knee region, and for increases in the size of painful areas. For example, the pressure needed to cause pain, applied to various parts of the body, is lower among these patients than among normal controls of the same gender and age $^{(5)}$. With sensitization of the localized pain areas and bombardment of the central nervous system with neuron impulses, the adjacent segments start to become progressively sensitized. One important finding is that the degree of increase in sensitization correlates with the pain level.

\section{PAIN MANAGEMENT}

In the light of this emerging evidence suggesting that the central nervous system has a role in the physiopathology of pain among patients with knee arthrosis, the structures of the central nervous system should also be considered to be therapeutic targets, instead of administering purely local treatment with common analgesics, anti-inflammatory agents and non-pharmacological measures.

We often see patients who, despite undergoing correct orthopedic treatment, persistently present painful symptoms. These symptoms are generally segmental pains along the thigh and lower leg.

To understand these symptoms, we studied ${ }^{(5)}$ occurrences of segmental pain in the region of the vastus medialis, long adductor, anterior tibial and peroneus longus muscles that was associated with cutaneous hyperalgesia in these regions, among 62 patients with knee osteoarthrosis who were awaiting treatment consisting of total arthroplasty. We found that these symptoms occurred more frequently among these patients than among 22 patients of the same sex and age who had not had any painful symptoms in the lower limbs for the past year $(p<0.001)$.

There is radiological evidence that persistent pain leads to atrophy of the cerebral cortex, and that this improves with adequate treatment for this pain. If the participation of the central nervous system in the genesis of chronic pain like the pain caused by knee arthrosis is neglected, a mechanism that might explain the persistent pain seen in up to $60 \%$ of such patients will remain unknown.

The use of physiotherapeutic means and centrally acting drugs such as antidepressants ${ }^{(28)}$ needs to be taken into consideration in treating these patients.

\section{FINAL REMARKS}

In analyzing the pain presented by patients with knee arthrosis, which is pain that evolves chronically and is refractory to the usual orthopedic treatment, significant changes in cortical areas that are associated with affective and emotional processing need to be taken into consideration.

Among these patients, it is of fundamental importance to reduce or even to prevent amplification of the symptoms caused by continual activation of these areas. 


\section{REFERÊNCIAS}

1. Altman R, Asch E, Bloch D, Bole G, Borenstein D, Brandt K, et al Development of criteria for the classification and reporting of osteoarthritis. Classification of osteoarthritis of the knee. Diagnostic and Therapeutic Criteria Committee of the American Rheumatism Association. Arthritis Rheum. 1986;29(8):1039-49.

2. Felson DT, Lawrence RC, Hochberg MC, McAlindon T, Dieppe PA, Minor MA et al. Osteoarthritis: new insights. Part 2: treatment approaches. Ann Intern Med. 2000;133(9):726-37.

3. Doherty M. Pain in osteoarthritis. In: Giamberardino MA, editor. Pain 2002 - An updated Review: Refresher course syllabus. Seattle, WA: IASP Press; 2002 p. 51-7.

4. Recommendations for the medical management of osteoarthritis of the hip and knee: 2000 update. American College of Rheumatology Subcommittee on Osteoarthritis Guidelines. Arthritis Rheum. 2000;43(9):1905-15.

5. Imamura M, Imamura ST, Kaziyama HH, Targino RA, Hsing WT, de Souza LP, Cutait MM, Fregni F, Camanho GL. Impact of nervous system hyperalgesia on pain, disability, and quality of life in patients with knee osteoarthritis: a controlled analysis. Arthritis Rheum. 2008;59(10):1424-31.

6. Woolf CJ; American College of Physicians; American Physiological Society Pain: moving from symptom control toward mechanism-specific pharmacologic management. Ann Intern Med. 2004;140(6):441-51.

7. Staud $R$. Are tender point injections beneficial: the role of tonic nociception in fibromyalgia. Curr Pharm Des. 2006;12(1):23-7.

8. Staud R, Spaeth M. Psychophysical and neurochemical abnormalities of pain processing in fibromyalgia. CNS Spectr. 2008;13(3 Suppl 5):12-7.

9. Woolf CJ, Salter MW. Neuronal plasticity: increasing the gain in pain. Science. 2000;288(5472):1765-9.

10. Staud R, Cannon RC, Mauderli AP, Robinson ME, Price DD, Vierck CJ Jr. Temporal summation of pain from mechanical stimulation of muscle tissue in norma controls and subjects with fibromyalgia syndrome. Pain. 2003;102(1-2):87-95.

11. Abeles AM, Pillinger MH, Solitar BM, Abeles M. Narrative review: the pathophysiology of fibromyalgia. Ann Intern Med. 2007;146(10):726-34.

12. Lawson K. Treatment options and patient perspectives in the management of fibromyalgia: future trends. Neuropsychiatr Dis Treat. 2008;4(6):1059-71.

13. Gracely RH, Petzke F, Wolf JM, Clauw DJ. Functional magnetic resonance imaging evidence of augmented pain processing in fibromyalgia. Arthritis Rheum. 2002;46(5):1333-43.

14. Giesecke T, Gracely RH, Grant MA, Nachemson A, Petzke F, Williams DA, et al. Evidence of augmented central pain processing in idiopathic chronic low back pain. Arthritis Rheum. 2004;50(2):613-23.

15. Gwilym SE, Keltner JR, Warnaby CE, Carr AJ, Chizh B, Chessell I, et al Psychophysical and functional imaging evidence supporting the presence of central sensitization in a cohort of osteoarthritis patients. Arthritis Rheum. 2009;61(9):1226-34.

16. Creamer $P$, Hunt M, Dieppe P. Pain mechanisms in osteoarthritis of the knee: effect of intraarticular anesthetic. J Rheumatol. 1996;23(6):1031-6.

17. Farrell M, Gibson S, McMeeken J, Helme R. Pain and hyperalgesia in osteoarthritis of the hands. J Rheumatol. 2000;27(2):441-7.

18. Kosek E, Ordeberg G. Lack of pressure pain modulation by heterotopic noxious conditioning stimulation in patients with painful osteoarthritis before, but not following, surgical pain relief. Pain. 2000;88(1):69-78.

19. Bajaj P, Bajaj P, Graven-Nielsen T, Arendt-Nielsen L. Osteoarthritis and its association with muscle hyperalgesia: an experimental controlled study. Pain. 2001;93(2):107-14

20. Shah JP, Phillips TM, Danoff JV, Gerber LH. An in vivo microanalytical technique for measuring the local biochemical milieu of human skeletal muscle. J Appl Physiol. 2005;99(5):1977-84

21. Shah JP, Danoff JV, Desai MJ, Parikh S, Nakamura LY, Phillips TM, et al. Biochemicals associated with pain and inflammation are elevated in sites near to and remote from active myofascial trigger points. Arch Phys Med Rehabil. 2008;89(1):16-23.

22. Schadrack J, Neto FL, Ableitner A, Castro-Lopes JM, Willoch F, Bartenstein P, et al. Metabolic activity changes in the rat spinal cord during adjuvant monoarthritis. Neuroscience. 1999;94(2):595-605.

23. Kulkarni B, Bentley DE, Elliott R, Julyan PJ, Boger E, Watson A, et al.. Arthritic pain is processed in brain areas concerned with emotions and fear. Arthritis Rheum. 2007;56(4):1345-54

24. Clauw DJ, Witter J. Pain and rheumatology: thinking outside the joint. Arthritis Rheum. 2009;60(2):321-4.

25. Fischer AA, Imamura M, New concepts in the diagnosis and management of musculoskeletal pain. In: Lennard TA, editor. Pain procedures in clinical practice. 2nd ed. Philadelphia: Hanley \& Belfus; 2000. p.213-29.

26. Fischer AA, Imamura M, Dubo H, O’Young BJ, Cassius DA, Spinal segmental sensitization: diagnosis and treatment. In: O'Young BJ, Young MA, Steins SA, editors. Physical medicine and rehabilitation secrets. 3rd ed. Philadelphia: Elsevier; 2007. p. 610-25.

27. Hoheisel U, Mense S, Simons DG, Yu XM. Appearance of new receptive fields in rat dorsal horn neurons following noxious stimulation of skeletal muscle: a model for referral of muscle pain? Neurosci Lett. 1993;153(1):9-12.

28. Chappell AS, Ossanna MJ, Liu-Seifert H, lyengar S, Skljarevski V, Li LC, et al. Duloxetine, a centrally acting analgesic, in the treatment of patients with osteoarthritis knee pain: a 13-week, randomized, placebo-controlled trial. Pain. 2009;146(3):253-60 